\title{
Seismic Assessment and Retrofitting of Existing RC Structures: SeismoStruct and SeismoBuild Implementation
}

\author{
Reza Latifi ${ }^{1, *}$, Rahimeh Rouhi $^{2}$ \\ ${ }^{1}$ School of Engineering, University of Bologna, 40136, Italy \\ ${ }^{2}$ Université de Lorraine, CNRS, LORIA, F-54000 Nancy, France \\ Received January 18, 2020 ; Revised February 25, 2020; Accepted March 12, 2020
}

Copyright $\odot 2020$ by authors, all rights reserved. Authors agree that this article remains permanently open access under the terms of the Creative Commons Attribution License 4.0 International License

\begin{abstract}
Many existing structures require seismic retrofitting based on the latest findings and standards. Most of the works presented in the literature have considered the effect of different retrofitting solutions on the seismic behavior of the structures. Therefore, a comprehensive comparison of these techniques is needed to select the most effective one. Hence, in this paper, we present a comparative study of the most useful retrofitting techniques of RC structures, using the recent and updated versions of the standards and design codes. The merits and weaknesses of the most useful retrofit techniques and the available approaches are presented and demonstrated, which utilizes SeismoStruct and SeismoBuild. A 2-story $\mathrm{RC}$ building with the lack of transversal and longitudinal reinforcements is retrofitted by some techniques such as $\mathrm{RC}$ jacketing, $\mathrm{RC}$ walls, and FRP wrapping. The structural response of the retrofitted buildings is compared with the initial one. The comparison of the results shows that using $\mathrm{RC}$ walls at the perimeter of the existing buildings is the most efficient way in reducing demand capacity ratio (DCR) of other structural members, maximum roof displacements, and building fundamental period. The results of the pushover analysis of the buildings retrofitted by RC jackets and RC walls indicate a significant increase in the capacity curves.
\end{abstract}

Keywords Retrofitting, RC Jacketing, FRP Wrapping, RC Walls

\section{Introduction}

Earthquake engineering has been developed adequately in recent years, to ensure that well-detailed, recently designed buildings usually show enough strength, stiffness, and ductility to resist severe earthquake ground motion. Most of the existing buildings were built many years ago, when engineering science was not at today's level of understanding, and the building codes were less rigorous. Hence, for the buildings constructed according to older codes, the focus had been put only on the vertical gravity forces, with limited or no concern for the lateral resisting system [1].

Besides, the accelerated progress in all sciences, particularly earthquake engineering during the last decades, has completely changed the design philosophy and codes. Hence, the vast majority of the structures are vulnerable in high-intensity seismic actions and show vital needs to structural upgrading and retrofit, i.e., lack of stiffness, ductility, or resistance to lateral loads and soft stories [2]. Table 1 illustrates the comparison of the most useful retrofit and strengthening techniques for RC buildings. Most of the methods provide an increase in the member's strength and the ductility while using FRPs and steel plates do not affect the structural stiffness. The base isolation system decreases the seismic demand of the structure and does not modify the capacity [3]. 
Table 1. Comparison of the useful retrofitting techniques

\begin{tabular}{|c|c|c|c|c|}
\hline & Strength & Stiffness & Ductility & $\checkmark$ \\
\hline RC Jackets & $\checkmark$ & $\checkmark$ & $\checkmark$ & $\checkmark$ \\
\hline New RC walls & $\checkmark$ & $\checkmark$ & $\checkmark$ & \\
\hline Steel Bracing & $\checkmark$ & & $\checkmark$ & \\
\hline FRP Wrapping & $\checkmark$ & & $\checkmark$ \\
\hline FRP Laminates & $\checkmark$ & & $\checkmark$ \\
\hline Steel Plates & & & \\
\hline
\end{tabular}

Ten rehabilitation methods tested by Ramírez [4] showed that concrete jackets are easy to construct and are one of the most useful and cost-efficient techniques; Vandoros and Dritsos, [5] with an experimental study proved that RC jacketing and CFRPs increased the columns' strength, and ductility considerably. Also, RC jacketing increases member stiffness. Krainskyi et al., [6] examined ten strengthened $\mathrm{RC}$ columns with the same design procedure, but under various loadings, and noted that the capacity increased approximately $290 \%$ by doubling the columns' cross-sections. The studies carried out by Balsamo et al., [7] proved that FRP-wrapping enables the development of large-displacement or chord rotation ductility parameters. Ferracuti et al. [8] investigated the behavior of FRP-retrofitted RC frames under seismic actions and showed that the activation of brittle failure modes, for instance, soft-story mechanisms, may be prevented using this method.

Folic et al. [9] studied the impact of adding shear walls for seismic strengthening of old buildings made up of RC frames with insufficient resistance to lateral load. They demonstrated that adding shear walls could successfully improve horizontal rigidity, bearing capacity, ductility, and dissipation capability of seismic energy. Most of the works presented in the literature have been conducted to explore the effect of different retrofitting solutions on the seismic behavior of the structure. However, the literature needs a comprehensive comparison of these techniques. Hence, in this paper, we present a comparative study between some of the most useful retrofitting techniques of RC structures, using the recent and updated versions of the standards and design codes.

\section{Model Description}

The building under consideration in this paper is a 2 -story RC building with plan dimensions $11 \mathrm{~m} \times 14 \mathrm{~m}$ and an average inter-story height of $3 \mathrm{~m}$, see Figure 1 and Figure 2. The average height of the slabs is $30 \mathrm{~cm}$. The majority of beams feature typical dimensions $0.2 \mathrm{~m} \times 0.5 \mathrm{~m}$ with an average length of $4 \mathrm{~m}$. There are two types of columns whose dimensions are $0.4 \mathrm{~m} \times 0.4 \mathrm{~m}$ with the longitudinal reinforcement area ratio $0.5 \%$ and $1.0 \mathrm{~m} \times$ $2.0 \mathrm{~m}$ with the longitudinal reinforcement area ratio $0.8 \%$ and stirrups $\emptyset 6 \mathrm{~mm} @ 25 \mathrm{~cm}$. All the sections are without sufficient longitudinal and transverse reinforcement. The longitudinal and transversal reinforcements are considered constant along with the elements' height.

The majority of beams feature typical dimensions of $20 \mathrm{~cm} \times 50 \mathrm{~cm}$. Different longitudinal reinforcement is introduced in the middle of the beam and at its two edges, while the transversal reinforcement consists of $\varnothing 10 \mathrm{~mm} @ 15 \mathrm{~cm}$ stirrups along the member length. The beams' structural details include u2Ø16mm, $14 \varnothing 16 \mathrm{~mm}$, s $2 \varnothing 14 \mathrm{~mm}$ for the reinforcement of the middle part, and $\mathrm{u} 4 \varnothing 16 \mathrm{~mm}, 12 \varnothing 16 \mathrm{~mm}, \mathrm{~s} 2 \varnothing 14 \mathrm{~mm}$ at the two edges. The slabs' top and bottom reinforcement are typically equal to $\varnothing 10 \mathrm{~mm} @ 10 \mathrm{~cm}$. 


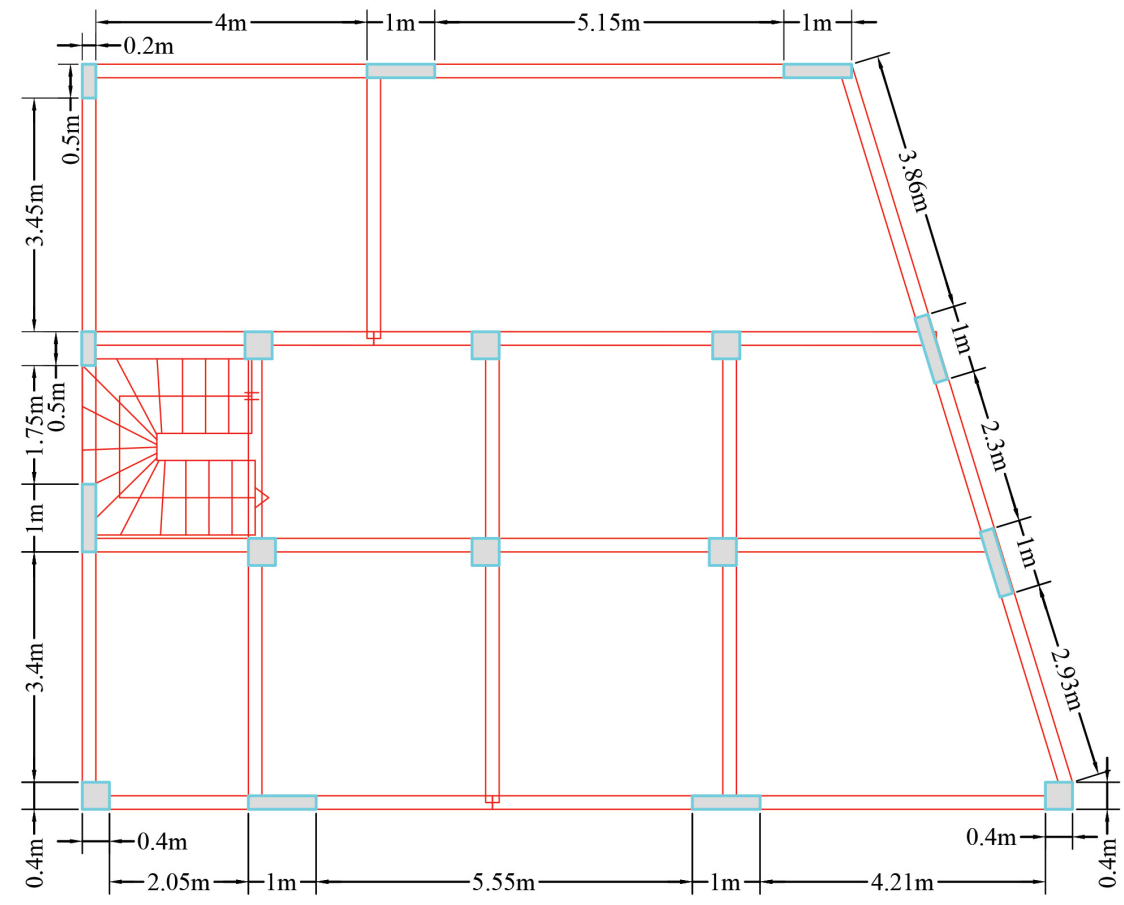

Figure 1. Plan view of the first and second floors

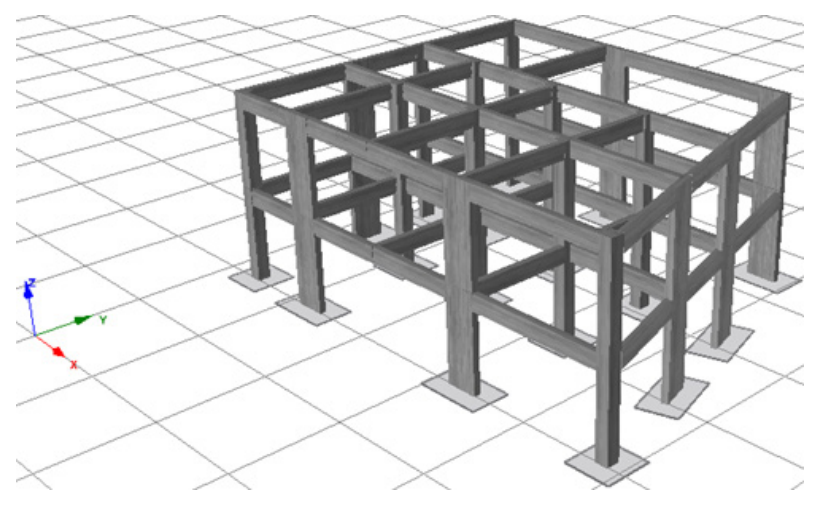

Figure 2. 3-D view of the building

The knowledge level achieved from an extended in-situ inspection or as-built drawings determines the proper method of analysis, as well as the values for the confidence factors (CF). The CF considered 1.20 in this research.

The material of longitudinal reinforcement steel in SeismoStruct is defined by Menegotto and Pinto (1973) model [10]. The Mander et al., (1988) [11] concrete model is used for both the existing and the new/retrofitted members. The confinement effect is a function of section geometry and the longitudinal and transversal reinforcement layout. Expected (mean) strength of the existing concrete strength $\left(f_{c m}\right)$ is estimated $20 \mathrm{MPa}$, with a lower - bound strength of $16 \mathrm{MPa}$ which is the mean minus one standard deviation $\left(f_{c m}-\sigma\right)$. The new concrete grade is $\mathrm{C} 25 / 30\left(f_{c k}=25 M P a\right)$. For the existing and new longitudinal and transversal reinforcement steel, Class S400 and Class S500 are chosen, respectively. The material safety factors for the concrete and steel are $\gamma_{c}=1.5$, $\gamma_{s}=1.15$ respectively. The slabs are modelled as the rigid diaphragm, and beam-column joints' end rigidity has been taken into consideration. Cross-sections behaviour is modelled by using the fiber model, meaning that each fiber is associated with a uniaxial stress-strain relationship [12].

The contribution of gravity loads to the effective seismic weight is obtained by the combination rule established in equation (1) of EN 1998-1 (2004) [13].

$$
\sum_{j \geq 1} G_{k, j} "+" \sum_{i \geq 1} \psi_{E, i} Q_{k, i}
$$

With $\sum_{j \geq 1} G_{k, j}$ accounting for the summary of dead loads and the combination coefficients $\psi_{E, i}$ take into account the likelihood of the live loads $\left(Q_{k, i}\right)$ not being present over the entire structure during the earthquake. Permanent loads $(\mathrm{G})$ for the slabs, cantilevers, and stairs are $5.10 \mathrm{KN} / \mathrm{m}^{2}, 7.26 \mathrm{KN} / \mathrm{m}^{2}$, and $5.1 \mathrm{KN} / \mathrm{m}^{2}$, respectively. Live loads $(\mathrm{Q})$ for slabs, cantilevers, and stairs are 2.00 $\mathrm{KN} / \mathrm{m}^{2}, 2.50 \mathrm{KN} / \mathrm{m}^{2}$, and $2.00 \mathrm{KN} / \mathrm{m}^{2}$, respectively. Permanent and Live loads coefficients are 1.00 and 0.30 , respectively. According to EN1998-3 Section 2.1, performance requirements refer to the state of damage in the structure defined through three limit states, namely Near Collapse (NC), Significant Damage (SD), and Damage Limitation (DL) [14]. To draw the elastic and design pseudo-acceleration response spectra shown in Figure 3, the damping ratio considered $5.0 \%$, and the Importance Class II, PGA is $0.160 \mathrm{~g}$ for the return period of 475 years, and soil class B of type 1, according to EN1998-1 [13]. 


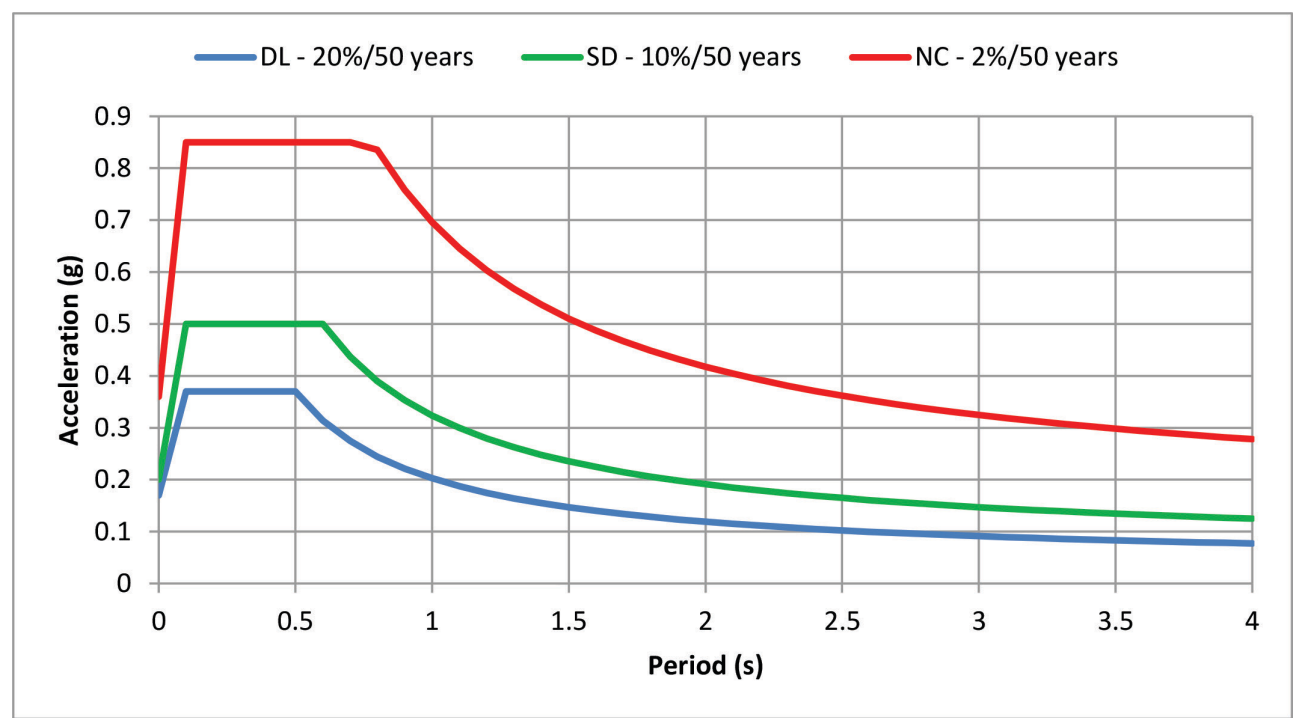

Figure 3. Code-based Spectra for the limit states DL, SD, and NC

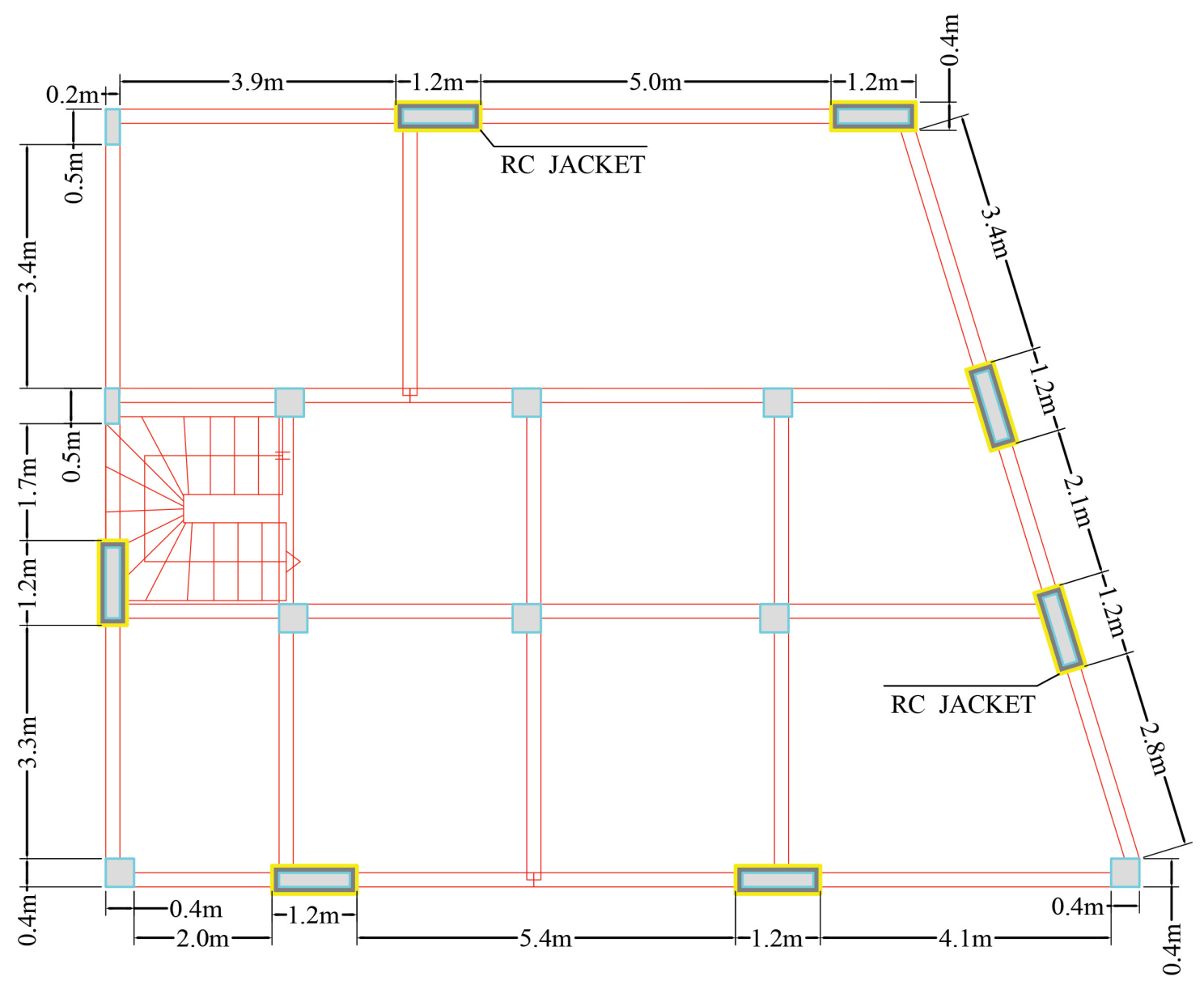

Figure 4. Retrofitting scheme with RC jackets 


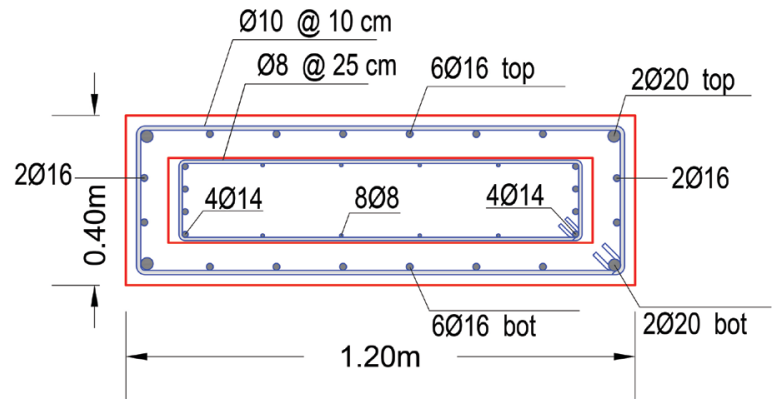

Figure 5. Layout of the jacketed sections

\subsection{Retrofitting with RC Jackets}

This method includes the additional RC layer outside the perimeter of the existing member using longitudinal and transversal reinforcements. The jacket's concrete grade and the reinforcement steel grade is $\mathrm{C} 25 / 30$, and B500c respectively. The longitudinal reinforcement of a typical jacket could be $4 \varnothing 20+4 \varnothing 16$, although there has been a significant increase in the shear reinforcement of the columns with stirrups of Ø10/10. A significant increase in strength, ductility, and stiffness of the existing members can be achieved by applying this technique. A decrease in seismic demand of other members that are not retrofitted takes place, so strengthening of some structural members may be adequate [15]. Figure 4 and Figure 5 show the retrofitting scheme and layout of the jacketed section, as they were modeled in SeismoBuild.

\subsection{Retrofitting with FRP Wrapping}

FRP is a composite material made up of a polymer matrix reinforced with fibers. The fibers are usually carbon (CFRP), glass (GFRP), aramid (AFRP), or rarely basalt. FRP materials are commonly applied to existing RC members as external reinforcement due to their high tensile strength and low weight (compared to conventional steel) to increase their flexural and shear strength [16]. It is noted that the strengthening of structural members with FRPs, though considerably increases their strength, does not change their stiffness, and does not affect the stiffness distribution of the entire structure. As it is shown in Figure 6 , the retrofit is carried out in all failed columns in code-based checks and with one layer of a relatively strong FRP wrap (SikaWrap 600C). The characteristic and nominal values of the fiber thickness are $0.331 \mathrm{~mm}$, tensile strength $3800 \mathrm{MPa}$, tensile modulus $242000 \mathrm{MPa}$, and the elongation $1.55 \%$.

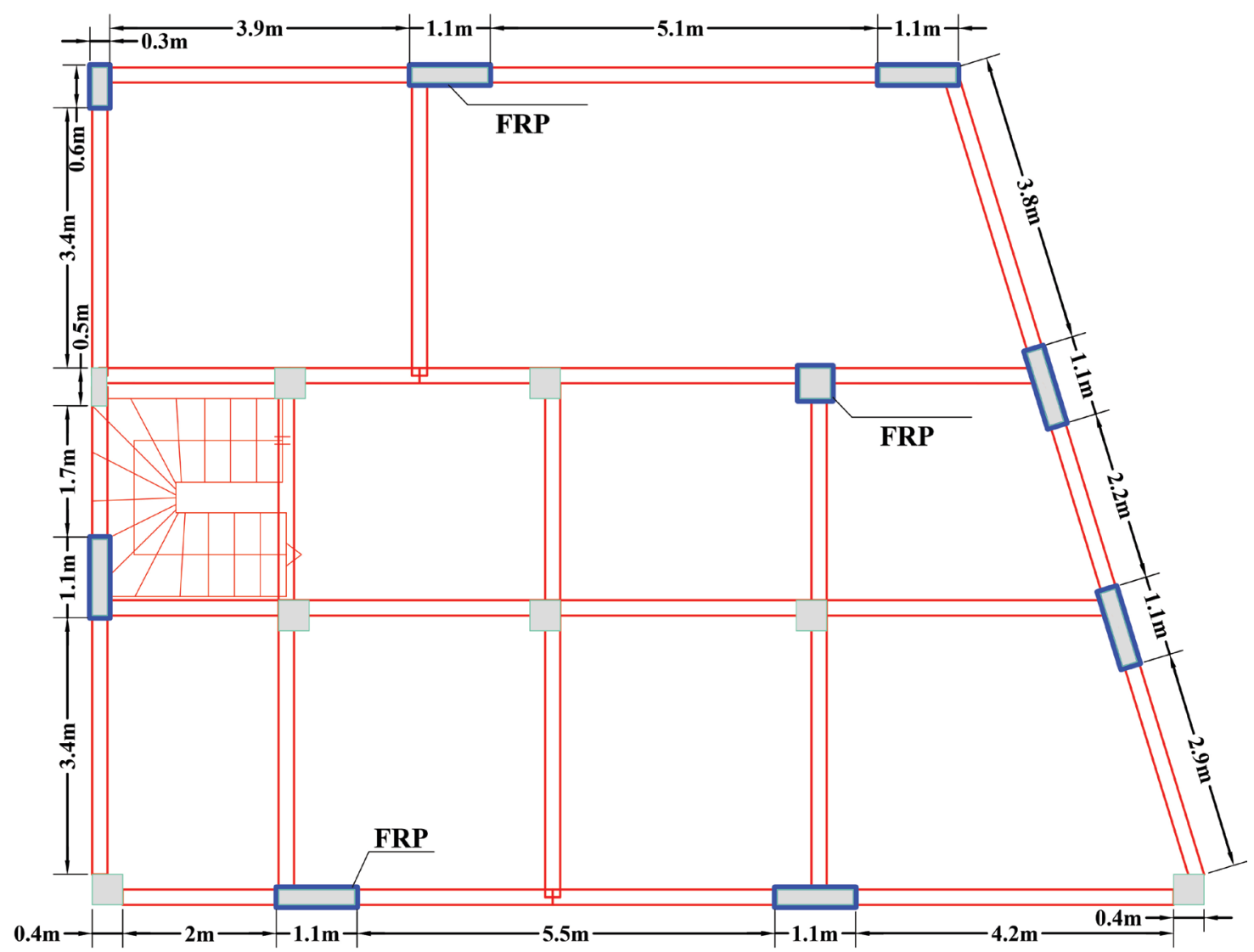

Figure 6. Retrofitting scheme with FRP wrapping 


\subsection{Retrofitting with RC Walls}

$\mathrm{RC}$ walls can have a very beneficial effect on the seismic performance of existing buildings, providing a significant increase in strength, stiffness, and ductility. Because of the substantial stiffness of the shear walls concerning the columns, the new walls are usually added in the symmetric scheme, in order to prevent torsional effects in the seismic behavior, and in the entire height of the building, in order to prevent significant irregularities in elevation [15]. RC walls may be added either externally, in the perimeter of the building, or internally, inside the building bays, usually surrounding the existing columns. The seismic demand on the other vertical structural members of the building significantly reduced since the walls can undertake most of the base and the story shears. Hence, new walls are commonly introduced without the strengthening of the other existing columns [12]. As it is shown in Figure 7, the retrofit is carried out with seven new RC walls with two types of cross-sections at the perimeter and extended at the full height of the building. Figure 8 shows the reinforcement layout of $\mathrm{RC}$ walls.

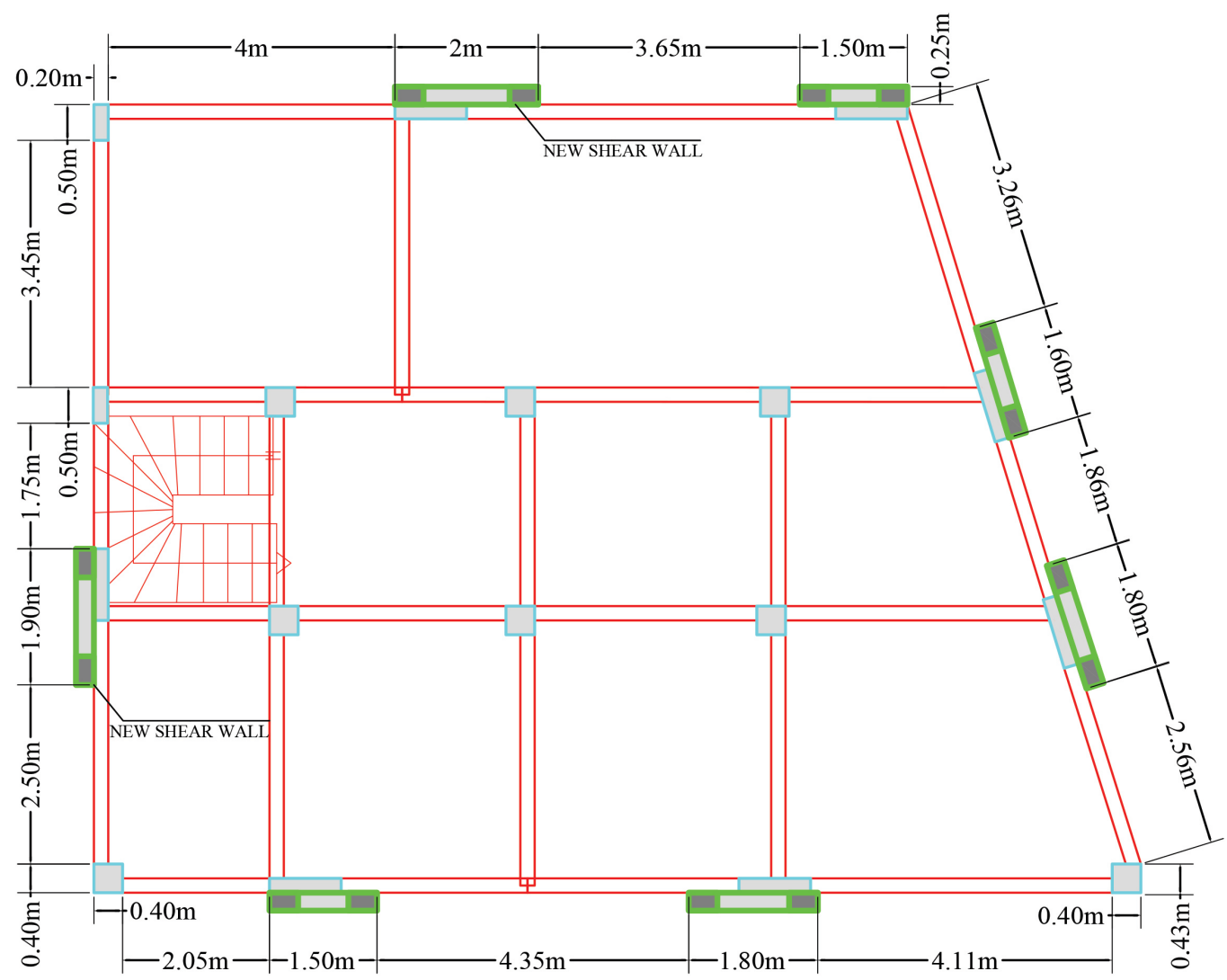

Figure 7. Retrofitting scheme with RC walls
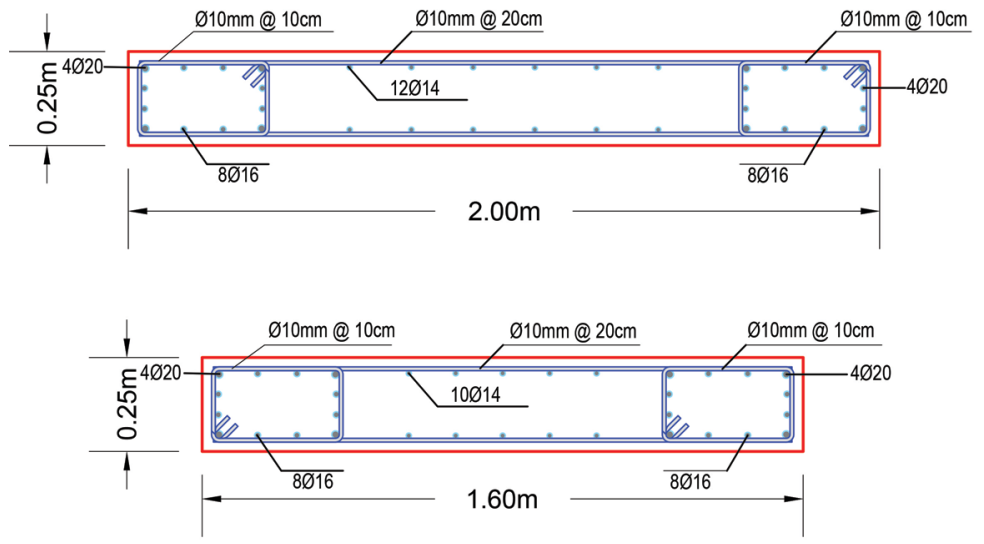

Figure 8. Layout of RC wall sections 


\section{Analysis and Code-Based Checks}

According to Eurocode 8, Part 1 and 3, the effects of the seismic action along with the effects of the permanent and variable loads are evaluated by using one of the following methods $[13,14]$ :

1. Lateral force analysis, subject to limitations specified in EN 1998-1:2004 Section 4.3.3.2.1 with the addition of Section 4.4.2 of EN 1998-3:2005;

2. Modal response spectrum analysis, subject to limitations specified in EN 1998-1:2004 Section 4.3.3.3.1 with the addition of the conditions specified in Section 4.2 of EN 1198-3:2005;

3. Non-linear static (pushover) analysis, according to Sections 4.3.3.4.2.1 of EN1998-1:2004 and 4.4.4 of EN 1998-3:2005;

4. Non-linear time history dynamic analysis, according to the procedure of Section 4.3.3.4.3. of $\mathrm{EN}$ 1998-1:2004;

5. q-factor approach, as described in EN 1998-1:2004 Section 4.3.3.2 or 4.3.3.3, as appropriate.

In this paper, the eigenvalue, pushover, and dynamic analysis and the code-based checks have been carried out by using SeismoStruct and SeismoBuild software.

\subsection{Nonlinear Static Analysis}

Pushover analysis is carried out under constant gravity loads, and increasing lateral forces applied at the location of the masses to simulate the inertia forces induced by the seismic action [17]. The introduced vertical loads applied to the $3 \mathrm{D}$ model, in addition to incremental loads, are equal to $1.0 \mathrm{G}+0.3 \mathrm{Q}$. The horizontal load pattern may be applied with different load distributions, i.e., uniform, modal, and adoptive patterns in both positive and negative directions or simultaneously by employing the $30 \%$ rule combinations [18].

Each pushover analysis leads to a capacity curve, which is a relationship between the total base shear and the control node horizontal displacement. The centre of mass at each floor may be considered displaced from its nominal location in each direction by an accidental eccentricity equal to $5 \%$ of the floor-dimension perpendicular to the direction of the seismic action [19].

\subsection{Chord Rotation Capacity Checks}

The structural demand associated with specified target displacement should satisfy the verification criteria. Chord rotation capacity at the limit state of near collapse (NC) is the value of the total chord rotation capacity (elastic plus inelastic part) at ultimate of concrete members under cyclic loading $\left(\theta_{u m}\right)$. The chord rotation capacity corresponding to significant damage (SD) limit state is assumed to be $\frac{3}{4}$ of the ultimate chord rotation $\left(\theta_{S D}=\frac{3}{4} \theta_{u m}\right)$. The chord rotation at yielding $\left(\theta_{y}\right)$ corresponds to the limit state of damage limitation (DL).

\subsection{Member and Joints Shear Capacity Checks}

The diagonal compression induced in the joint by the diagonal strut mechanism should not exceed the compressive strength of concrete. Adequate joint confinement should be provided to limit the maximum diagonal tensile stress of concrete. Also, adequate vertical reinforcement of the column passing through the joint should be provided. The most appropriate retrofit method to upgrade the beam-column joint seismic behavior is using RC jackets for the columns with the reinforcement correctly lapped between the different floors and the stirrups of the jackets continuing inside the beam area [20].

\section{Results and Discussions}

Effective modal mass ratios and periods of the fundamental mode are illustrated in Table 2. For the initial building eigenvalue analysis, and the effective modal mass ratio of $69.067 \%$ indicates the first mode in the Y-direction dominates the response. The first mode period of the building retrofitted by $\mathrm{RC}$ jackets and new $\mathrm{RC}$ walls decreases while this period for retrofitting by FRP wrapping is the same as the initial building since FRP wrapping does not increase the stiffness considerably.

Figure 9 illustrates the capacity curves based on the pushover analysis in Y-direction and the target displacements for the selected Limit States. The target displacements of the building retrofitted by $\mathrm{RC}$ jackets and $\mathrm{RC}$ walls are less than initial building and retrofitted by FRP wrapping.

The results for retrofitted building by $\mathrm{RC}$ walls for the SD limit state indicate a target displacement of $0.75 \mathrm{~cm}$ and a maximum building capacity of approximately $4900 \mathrm{kN}$ at a top displacement of $3.5 \mathrm{~cm}$. For retrofitted building by RC jackets, show a target displacement of $0.8 \mathrm{~cm}$ and a maximum building capacity of about $3600 \mathrm{kN}$ at a top displacement of $3.7 \mathrm{~cm}$. Also, the results of the retrofitted building by FRP wrapping indicate a target displacement of $1.8 \mathrm{~cm}$ and a maximum building capacity of $1800 \mathrm{kN}$ at a top displacement of $3.5 \mathrm{~cm}$. It has been shown that using $\mathrm{RC}$ walls and RC jackets may increase the base shear capacity by more than $100 \%$, while there is a substantial decrease in the calculated target displacement of roughly $60 \%$.

Almost in all the structural members of the initial and strengthened buildings, the chord rotation capacity checks pass the code-based checks criteria. Also, the maximum DCR in shear for the initial building, retrofitted by RC walls, RC jackets, and FRP wrapping, is about 1.51, 0.59, 0.98 , and 0.93 , respectively. In the dynamic time-history analysis, as it is prescribed in the different codes, the applied loading is always acceleration time-histories at the 
base of the building. In doing so, a single real accelerogram, acceleration of approximately $0.65 \mathrm{~g}$. As it is shown in which was recorded in the 1999 Chi-Chi earthquake in Figure 10, the roof displacement time history for the initial Taiwan, was applied in the y-direction. It has a peak building and retrofitted by FRP wrapping are almost the ground acceleration of $0.35 \mathrm{~g}$ and a maximum spectral same with a maximum of $1.5 \mathrm{~cm}$.

Table 2. Period and effective modal mass ratios of Mode

\begin{tabular}{|c|c|c|c|c|c|c|c|}
\hline \multirow{2}{*}{ Mode 1 } & \multirow{2}{*}{ Period (sec) } & \multicolumn{5}{|c|}{ Effective Modal Mass Percentages (\%) } \\
\cline { 3 - 9 } & & $\mathrm{Ux}$ & $\mathrm{Uy}$ & $\mathrm{Uz}$ & $\mathrm{Rx}$ & $\mathrm{Ry}$ & $\mathrm{Rz}$ \\
\hline Initial building & 0.198 & 19.306 & 69.061 & 0.000 & 2.621 & 0.678 & 0.002 \\
\hline RC Jacketing & 0.140 & 16.371 & 66.141 & 0.000 & 4.184 & 0.906 & 0.342 \\
\hline RC Walls & 0.128 & 8.071 & 72.782 & 0.000 & 4.690 & 0.427 & 0.000 \\
\hline FRP Wrapping & 0.198 & 19.306 & 69.061 & 0.000 & 2.621 & 0.678 & 0.002 \\
\hline
\end{tabular}

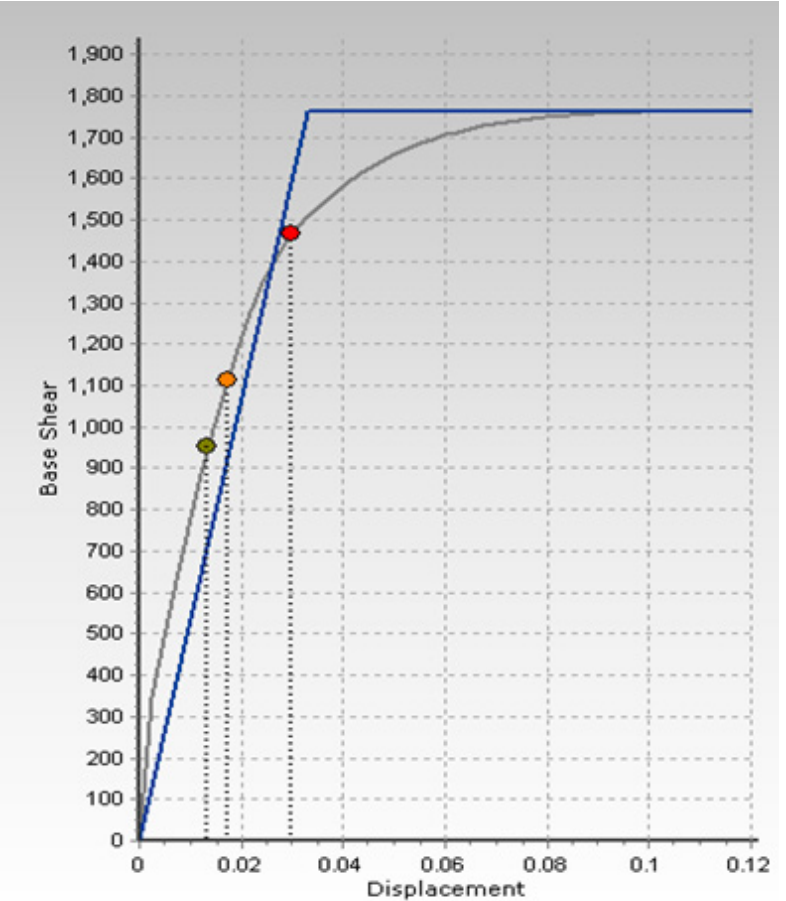

(a)

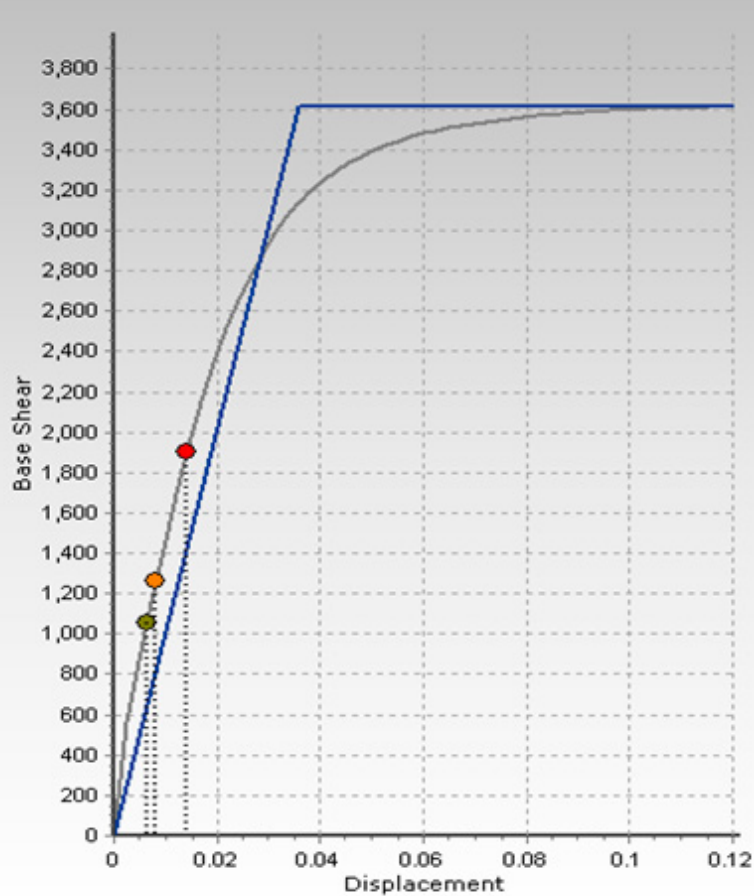

(b) 


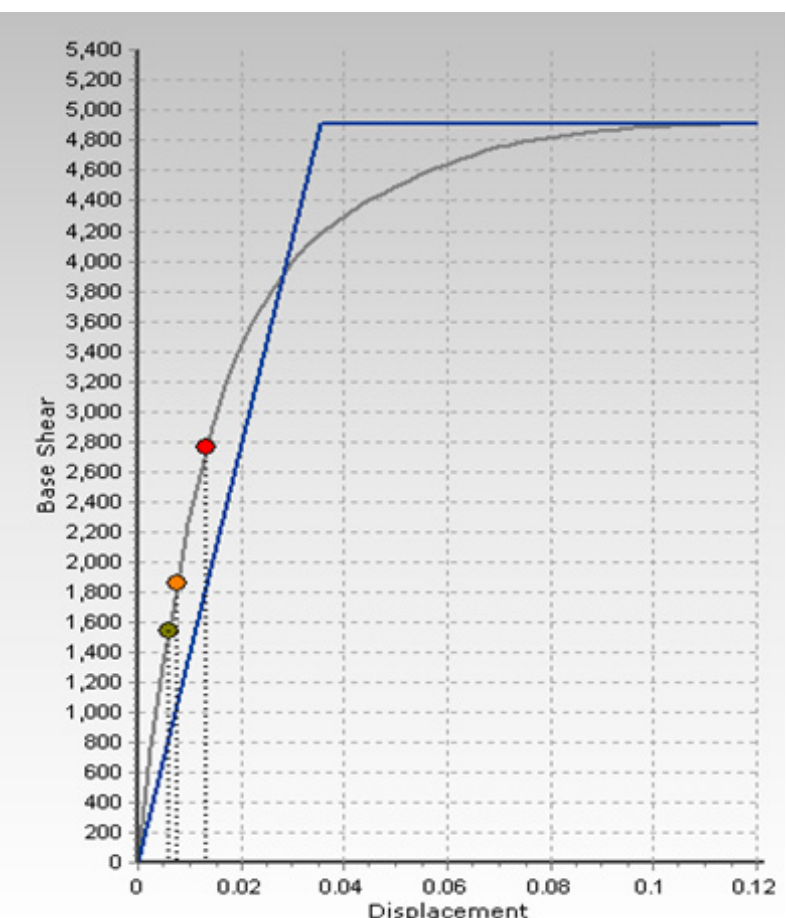

(c)

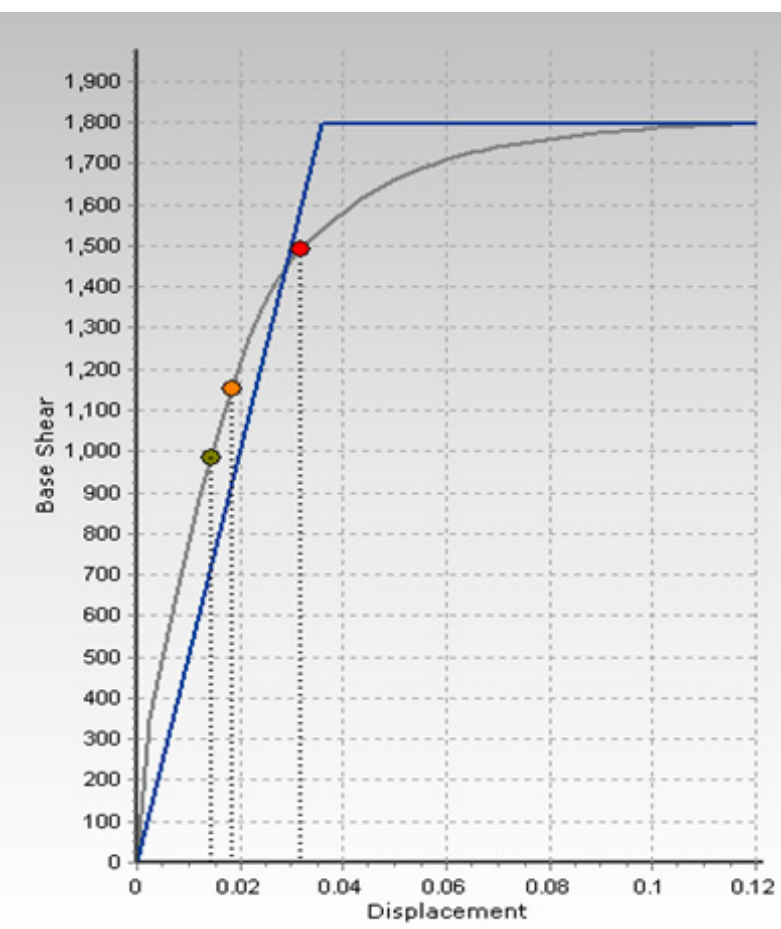

(d)

Figure 9. Capacity curves and the target displacements (a): Initial Building, (b): RC Jacket, (c): RC Walls, and (d): FRP Wrapping

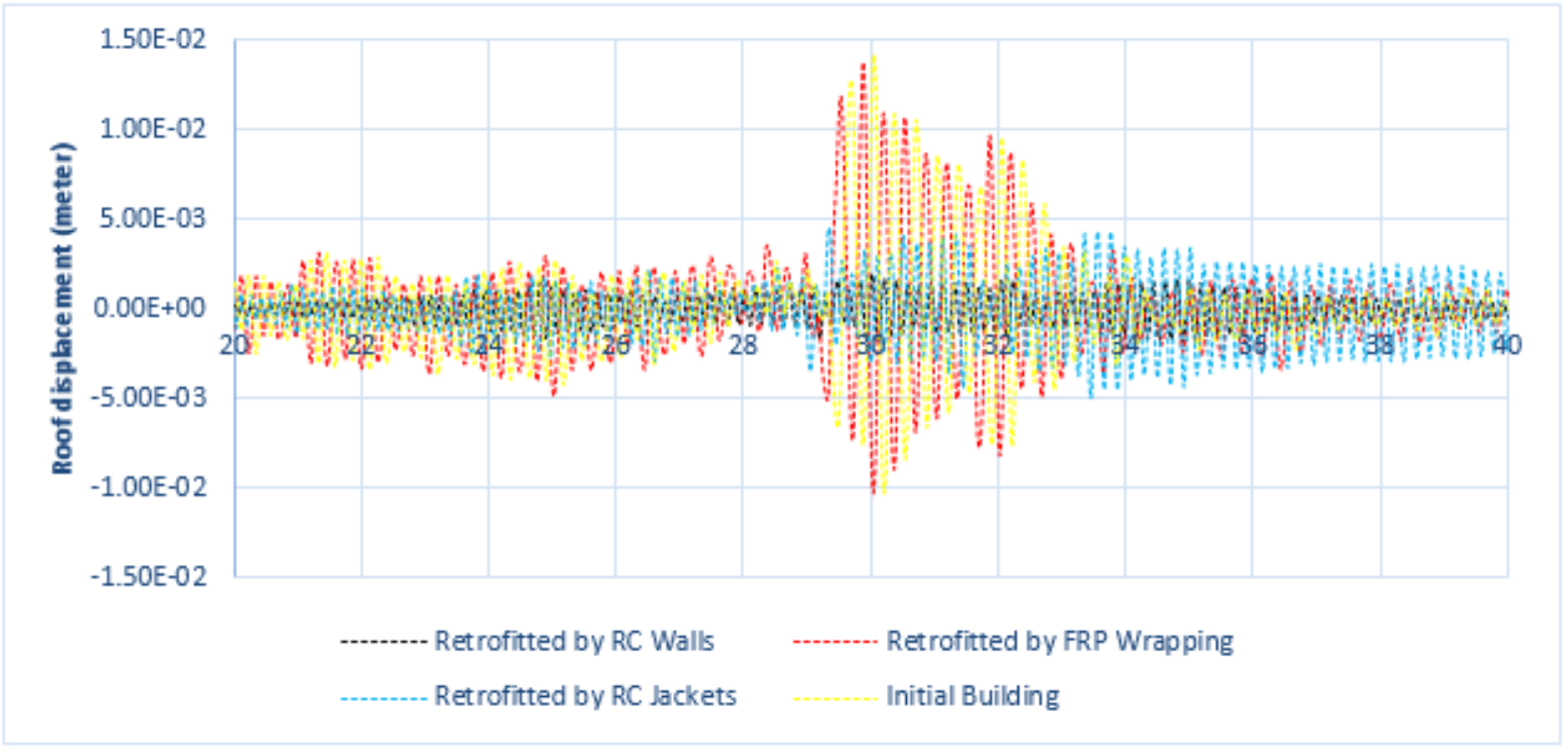

Figure 10. Roof displacement of the Initial and the retrofitted buildings

Although the dynamic behavior is very similar, shear checks are fulfilled much easier, because of the significant increase in shear capacity of the strengthened columns when retrofitting by FRP wrapping. The maximum roof displacement of the building strengthened with $\mathrm{RC}$ walls decreases $80 \%$, compared to the initial building, and about $50 \%$, compared to building retrofitted by RC jackets.

Shear walls can undertake most of the total base shear, and the other vertical members have to withstand a small percentage of the total seismic demand or base shear. Consequently, they pass the required checks with less or no intervention. Consequently, it would be better to introduce the elements such as RC walls at the perimeter, in order not to increase the cost for non-structural damage and not to prevent the operation of the building and use of RC jackets or FRP wraps in the columns of the ground floor. An alternative solution would be steel braces mostly for stiffness. The solution applies both FRP wraps and steel 
braces for better performance, FRPs for strength. The layout of the steel braces or jackets symmetric, in both $\mathrm{X}$ and $\mathrm{Y}$ directions, is preferred.

\section{Conclusions}

A 2-story RC building with a structural deficiency, i.e., lack of stirrups and longitudinal reinforcements, has been analysed, and the most useful seismic retrofitting solutions have been compared and discussed. The structural response of the initial and retrofitted models is analysed and compared. Shear capacity of strengthened members, which are the most critical aspect in RC structures, improved using these techniques. More specifically, the largest DCR in shear for the building has been strengthened by shear walls significantly decreases, concerning initial and retrofitted buildings by RC jackets and FRP wrapping. Eigenvalue analysis of the buildings retrofitted by RC jackets and RC walls indicates a significant increase in the stiffness of the building, i.e., a considerable decrease of more than $30 \%$ in the fundamental period concerning the initial building. The results of the pushover analysis of the buildings retrofitted by $\mathrm{RC}$ jackets and $\mathrm{RC}$ walls indicate a significant increase in the capacity of more than $100 \%$. Furthermore, as a result of increasing the building stiffness, there is a considerable decrease in the calculated target displacement of almost $60 \%$. The results from the Eigenvalue analysis, capacity curve, and target displacements of the building retrofitted by FRP wrapping are almost identical to the results of the initial building, although the retrofitted buildings show larger ductility.

\section{REFERENCES}

[1] ASCE/SEI 41-17, Seismic Evaluation and Retrofit of Existing Buildings. American Society of Civil Engineers, 2017.

[2] G. G. Penelis and G. G. Penelis, Concrete buildings in seismic regions.

[3] Fema, "Techniques for the Seismic Rehabilitation of Existing Buildings FEMA 547/2006 Edition,” 2006.

[4] J. L. Ramírez, "Ten concrete column repair methods," Constr. Build. Mater. vol. 10, no. 3, pp. 195-202, Apr. 1996.

[5] K. G. Vandoros and S. E. Dritsos, "Concrete jacket construction detail effectiveness when strengthening RC columns," Constr. Build. Mater. vol. 22, no. 3, pp. 264-276, Mar. 2008.

[6] P. Krainskyi, Z. Blikharskiy, and R. Khmil, "Experimental Investigation Of Reinforced Concrete Columns Strengthened By Jacketing," 2015.

[7] A. Balsamo, A. Colombo, G. Manfredi, P. Negro, and A. Prota, "Seismic behavior of a full-scale RC frame repaired using CFRP laminates," Eng. Struct., vol. 27, pp. 769-780, Apr. 2005.

[8] B. Ferracuti, M. Savoia, R. Pinho, S. Antoniou, and R. Francia, "Pushover analysis of FRP-retrofitted existing RC frame structures," 2007.

[9] R. Folic and P. Petronijevic, Seismic strengthening of buildings with RC walls. 2015.

[10] P. E. Menegotto, M., and Pinto, "Method of analysis of cyclically loaded RC plane frames including changes in geometry and non-elastic behavior of elements under normal force and bending," IABSE, vol. 13, 1973.

[11] J. B. Mander, M. J. Priestley, and R. Park, "Theoretical stress-strain model for confined concrete," J. Struct. Eng. (United States), vol. 114, no. 8, pp. 1804-1826, 1988.

[12] Seismosoft, "SeismoStruct 2020 - A computer program for static and dynamic nonlinear analysis of framed structures. http://seismosoft.com/."

[13] Eurocode 8, "Design of structures for earthquake resistance-Part 1: General rules, seismic actions and rules for buildings," 2004.

[14] Eurocode 8, "Design of structures for earthquake resistance-Part 3: Assessment and retrofitting of buildings," 2005.

[15] Seismosoft, "SeismoBuild 2020 - A Computer Program for Static and Dynamic Nonlinear Analysis of Framed Structures. http://seismosoft.com/."

[16] ACI Committee 440, “440.2R-08 Guide for the Design and Construction of Externally Bonded FRP Systems for Strengthening Concrete Structures."

[17] A. K. Chopra, Dynamics of Structures, 5th Editio. Pearson, 2017.

[18] S. Antoniou and R. Pinho, "Development and verification of a displacement-based adaptive pushover procedure," Earthq. Eng., 2004.

[19] S. Antoniou and R. Pinho, "Nonlinear Seismic Analysis of Framed Structures," in Engineering Dynamics and Vibrations, CRC Press, 2018, pp. 268-301.

[20] "Seismic Assessment \& Retrofitting of Existing RC Structures using SeismoStruct and SeismoBuild - Course Notes." [Online]. Available: https://ingeoexpert.com/en/co urses-online/seismic-assessment-seismobuild/. [Accessed: 21-Feb-2020]. 